\title{
Crystallization in Lead Tungsten Fluorophosphate Glasses
}

\author{
Rachel Prado Russo Delorenzo Nardi ${ }^{a}$, Celso Eduardo Braz ${ }^{a}$, Camila Pereira ${ }^{a}$,
}

Carolina Dakuzaku Freschi ${ }^{a}$, Jefferson Luiz Ferrari ${ }^{b}$, Andrea Simone Stucchi de Camargo ${ }^{c}$, Hellmut Eckert', Fabia Castro Cassanjes ${ }^{a}$, Gael Poirier ${ }^{a *}$

\author{
Instituto de Ciência e Tecnologia, Universidade Federal de Alfenas - UNIFAL-MG, \\ Campus de Poços de Caldas, Rodovia José Aurélio Vilela, 11999, Cidade Universitária, \\ CEP 37715-400, Poços de Caldas, MG, Brasil \\ ${ }^{b}$ Departamento de Ciências Naturais, Universidade Federal de São João Del Rei - UFSJ, \\ Campus Dom Bosco, Praça Dom Helvécio, 74, CEP 36301-160, São João Del Rei, MG, Brasil \\ 'Instituto de Física, Universidade de São Paulo - USP, Avenida Trabalhador São Carlense, 400, \\ CEP 13566-590, São Carlos, SP, Brasil
}

Received: November 13, 2014; Revised: January 12, 2015

\begin{abstract}
The glass forming ability was investigated in the codoped $\mathrm{Er}^{3+} / \mathrm{Yb}^{3+}$ ternary system $\mathrm{NaPO}_{3}-\mathrm{WO}_{3}-\mathrm{PbF}_{2}$ with increasing amounts of $\mathrm{PbF}_{2}$. It has been found that glass samples can be obtained for $\mathrm{PbF}_{2}$ contents ranging from $0 \mathrm{~mole} \%$ to $50 \mathrm{~mole} \%$ for the codoped samples and an undoped sample containing $60 \%$ of lead fluoride could also be vitrified. Thermal properties of the most $\mathrm{PbF}_{2}$ concentrated glasses exhibit strong dependence of the composition with a decrease of the glass transition temperatures and thermal stabilities against devitrification with increasing the lead fluoride content. These glass samples were heat-treated near the crystallization peaks and the X-ray diffraction measurements pointed out that the dominant phase which precipitates from the glass samples containing $40 \%$ and $50 \%$ of $\mathrm{PbF}_{2}$ is the lead fluorophosphate phase $\mathrm{Pb}_{5} \mathrm{~F}\left(\mathrm{PO}_{4}\right)_{3}$ whereas the sample containing $60 \%$ of $\mathrm{PbF}_{2}$ exhibits a preferential bulk crystallization of cubic lead fluoride $\beta-\mathrm{PbF}_{2}$.
\end{abstract}

Keywords: glasses, phosphate, lead fluoride

\section{Introduction}

Phosphate compounds are interesting glass formers and are largely used for their specific properties with respect to other classical glasses such as silicate, borate or germanate glasses. Particularly, they are well known for their small liquidus viscosity, softening temperatures, large UV transparency and high solubility for other glass modifiers or intermediaries such as alcaline, rare earth or transition metal compounds ${ }^{1-3}$. Another interesting behavior of phosphate glasses is their ability to incorporate fluoride compounds without reduction of the glass forming tendency. These vitreous materials are known as fluorophosphate glasses and are of great interest for rare earth luminescence since the fluoride compounds strongly reduce the phonon energy of the glass hos $\mathrm{t}^{4-5}$. Heavy metal fluoride compounds were also incorporated in several other glass formers and these materials were used to prepare the well-known ultratransparent glass ceramics ${ }^{6-7}$. These rare earth doped materials exhibit highly efficient luminescent properties since rare earth ions tend to migrate to the heavy metal fluoride crystalline phase during heat-treatment. On the other hand, tungsten phosphate glasses based on the binary system $\mathrm{NaPO}_{3}-\mathrm{WO}_{3}$ are well known for their great glass forming ability and very high thermal stability against devitrification due to the intermediary behavior of tungsten octahedra inside the metaphosphate network ${ }^{8-10}$. In addition,

*e-mail: gael.poirier@unifal-mg.edu.br
$\mathrm{WO}_{3}$ incorporation decreases the overall phonon energy of the phosphate glass with formation of $\mathrm{WO}_{6}$ clusters, resulting in interesting optical properties such as optical non linear absorption $^{11}$, photochromic effects ${ }^{12-13}$ and efficient luminescent properties when doped with rare-earth ${ }^{14}$. Based on these properties, it is suspected that tungsten phosphate glasses could be a suitable host for lead fluoride incorporation and preparation of rare-earth doped glass-ceramics containing $\mathrm{PbF}_{2}$ nanocrystals.

For these reasons, this work investigated the glass forming ability of codoped $\mathrm{Er}^{3+} / \mathrm{Yb}^{3+}$ samples in the ternary system $\mathrm{NaPO}_{3}-\mathrm{WO}_{3}-\mathrm{PbF}_{2}$ with a constant $\mathrm{NaPO}_{3} / \mathrm{WO}_{3}$ ratio of $3 / 2$ and increasing amounts of $\mathrm{PbF}_{2}$. The thermal properties were investigated by DSC and the most $\mathrm{PbF}_{2}$ concentrated samples were selected for investigation of the crystallization properties. These samples were heat-treated at specific temperatures and the resulting crystalline phases were identified by X-ray diffraction together with the dominant crystallization mechanism (bulk or surface) by DSC.

\section{Experimental Part}

Investigated compositions were prepared from the starting compounds $\mathrm{NH}_{4} \mathrm{H}_{2} \mathrm{PO}_{4} 48 \%$ in $\mathrm{P}_{2} \mathrm{O}_{5}, \mathrm{Na}_{2} \mathrm{CO}_{3} 98 \%, \mathrm{WO}_{3} 99,9 \%$, $\mathrm{PbF}_{2} 99,9 \%, \mathrm{Er}_{2} \mathrm{O}_{3} 99,99 \%$ and $\mathrm{Yb}_{2} \mathrm{O}_{3} 99,99 \%$, all from Aldrich. The starting powders were weighted using an 
analytical balance and grinded in an agate mortar. The resulting powder was transferred to a covered platinum crucible, heated at $400{ }^{\circ} \mathrm{C}$ for 1 hour to remove residual moisture and adsorbed gases, at $600{ }^{\circ} \mathrm{C}$ for 1 hour to promote $\mathrm{NH}_{4} \mathrm{H}_{2} \mathrm{PO}_{4}$ and $\mathrm{Na}_{2} \mathrm{CO}_{3}$ decomposition and at $850{ }^{\circ} \mathrm{C}$ for $10 \mathrm{~min}$ for melting of these starting powders. The materials were kept at this temperature for only $10 \mathrm{~min}$ to minimize fluoride losses and the melt was manually homogeneized after $5 \mathrm{~min}$ and $10 \mathrm{~min}$. Finally, the melt was poured in a steel mold preheated $20{ }^{\circ} \mathrm{C}$ below Tg and annealed at this temperature for 4 hour before cooling to room temperature inside the furnace. DSC curves were obtained on bulk and powder glass samples of $10 \mathrm{mg}$ in aluminum pans between $160^{\circ} \mathrm{C}$ and $470^{\circ} \mathrm{C}$ at $10^{\circ} \mathrm{C} /$ min under $\mathrm{N}_{2}$ atmosphere. These thermal analyzes were obtained using a DSC 200 F3 Maia calorimeter from Netzsch. X-ray diffraction measurements were performed on powder samples using a RigakuUltima IV diffractometer working at $40 \mathrm{KV}$ and $30 \mathrm{~mA}$ between $10^{\circ}$ and $70^{\circ}$ in continuous mode of $0,02^{\circ} \%$. The crystalline phases were identified according to X-ray powder diffraction patterns (PDF file) ${ }^{15}$.

\section{Results and Discussion}

The glass forming ability of $\mathrm{Er}^{3+} / \mathrm{Yb}^{3+}$-codoped compositions in the ternary system $(100-\mathrm{x})\left[0,6 \mathrm{NaPO}_{3}-0,4 \mathrm{WO}_{3}\right]-\mathrm{xPbF}_{2}$ were investigated by melt-quenching and it was found that glasses can be obtained from $\mathrm{x}=0$ to $\mathrm{x}=50$ whereas the sample with $\mathrm{x}=60$ crystallized under these cooling conditions. The molar $\mathrm{NaPO}_{3} / \mathrm{WO}_{3}$ ratio of $3 / 2$ was chosen because of the known high thermal stability of the binary glass $60 \mathrm{NaPO}_{3}-40 \mathrm{WO}_{3}$ and its suspected high ability to dissolve lead fluoride. In fact, this assumption could be verified since $\mathrm{PbF}_{2}$ incorporations as high as $50 \mathrm{~mole} \%$ were achieved for the rare-earth codoped compositions and $60 \mathrm{~mole} \%$ for the undoped composition as seen in Table 1 and Figure 1. Samples $0 \mathrm{PbEY}$ and $10 \mathrm{PbEY}$ also exhibit a strong dark color whereas samples containing $20 \%$ or more of $\mathrm{PbF}_{2}$ are transparent. This visible absorption has already been described in the binary system $\mathrm{NaPO}_{3}-\mathrm{WO}_{3}$ to be due to tungsten reduction from $\mathrm{W}^{6+}$ to $\mathrm{W}^{5+}$ in $\mathrm{WO}_{6}$ clusters $^{16}$. Visible and near infrared absorption is related with both electronic d-d transitions of $\mathrm{W}^{5+}$ and polaron transitions between $\mathrm{W}^{6+}$ and $\mathrm{W}^{5+}$, resulting in a very broad absorption band between $500 \mathrm{~nm}$ and $1300 \mathrm{~nm}$. This partial tungsten reduction taking place inside $\mathrm{WO}_{6}$ clusters is known in tungsten oxide crystalline materials and amorphous thin films and is commonly attributed to oxygen loss in order to reach lower free energy. In our case, it is suggested that a similar oxygen loss occurs during melting but is only possible in high $\mathrm{WO}_{3}$-concentrated glasses where tungsten oxide clusters are formed. Then, it is assumed that increasing $\mathrm{PbF}_{2}$ contents progressively breaks the covalent network and $\mathrm{W}-\mathrm{O}-\mathrm{W}$ bonds from these $\mathrm{WO}_{6}$ clusters and hinders the tungsten reduction. Since the main objective of this work is the selection of promising glass compositions for lead fluoride precipitation, the most $\mathrm{PbF}_{2}$ concentrated glass samples were chosen for further characterizations (40PbEY, $50 \mathrm{PbEY}$ and $60 \mathrm{~Pb})$. Thermal properties were investigated by DSC to determine the characteristic temperatures and thermal stability in function of the composition as shown in Figure 2 and Table 1. The first general information extracted from these results is that the thermal behavior of the glass samples is strongly dependent of the lead fluoride content. The glass transition temperature $\mathrm{Tg}$ decreases from $270{ }^{\circ} \mathrm{C}$ to $189^{\circ} \mathrm{C}$, which is in agreement with the expected modifier behavior of lead fluoride in the tungsten phosphate network. In fact, incorporation of fluoride compounds in covalent vitreous networks usually breaks the bridging bonds which are converted to terminal bonds. In our case, it is assumed that terminal P-F and/or W-F bonds are formed and result in a strong decrease of the network connectivity. Thus, the glass transition temperature as well as thermal stabilities decrease since this less connected network is less viscous and tend to crystallize. Another important result extracted from the DSC curves is the identification of different crystallization peaks for each sample. Glass $40 \mathrm{PbEY}$ exhibits a very weak exothermic event at $470{ }^{\circ} \mathrm{C}$ and an intense peak centered at $530{ }^{\circ} \mathrm{C}$. The baseline shift around $375^{\circ} \mathrm{C}$ could not be related with a crystallization event since heat treatment

Table 1. Molar compositions and characteristic temperatures of glass samples.

\begin{tabular}{|c|c|c|c|c|c|c|c|}
\hline Sample & Molar composition & Tg & $\mathbf{T} \mathbf{x}_{1}$ & $\mathbf{T c}_{1}$ & $\mathbf{T} \mathbf{x}_{2}$ & $\mathbf{T c}_{2}$ & $T x_{1}-T g$ \\
\hline $40 \mathrm{PbEY}$ & $35,64 \mathrm{NaPO}_{3}-23,76 \mathrm{WO}_{3}-40 \mathrm{PbF}_{2}-0,5 \mathrm{Yb}_{2} \mathrm{O}_{3}-0,1 \mathrm{Er}_{2} \mathrm{O}_{3}$ & $270^{\circ} \mathrm{C}$ & $456^{\circ} \mathrm{C}$ & $470^{\circ} \mathrm{C}$ & $509^{\circ} \mathrm{C}$ & $531^{\circ} \mathrm{C}$ & $186^{\circ} \mathrm{C}$ \\
\hline $50 \mathrm{PbEY}$ & $29,64 \mathrm{NaPO}_{3}-19,76 \mathrm{WO}_{3}-50 \mathrm{PbF}_{2}-0,5 \mathrm{Yb}_{2} \mathrm{O}_{3}-0,1 \mathrm{Er}_{2} \mathrm{O}_{3}$ & $237^{\circ} \mathrm{C}$ & $312^{\circ} \mathrm{C}$ & $325^{\circ} \mathrm{C}$ & $386^{\circ} \mathrm{C}$ & $397^{\circ} \mathrm{C}$ & $75^{\circ} \mathrm{C}$ \\
\hline $60 \mathrm{~Pb}$ & $24 \mathrm{NaPO}_{3}-16 \mathrm{WO}_{3}-60 \mathrm{PbF}_{2}$ & $189^{\circ} \mathrm{C}$ & $235^{\circ} \mathrm{C}$ & $250^{\circ} \mathrm{C}$ & $285^{\circ} \mathrm{C}$ & $301^{\circ} \mathrm{C}$ & $46^{\circ} \mathrm{C}$ \\
\hline
\end{tabular}

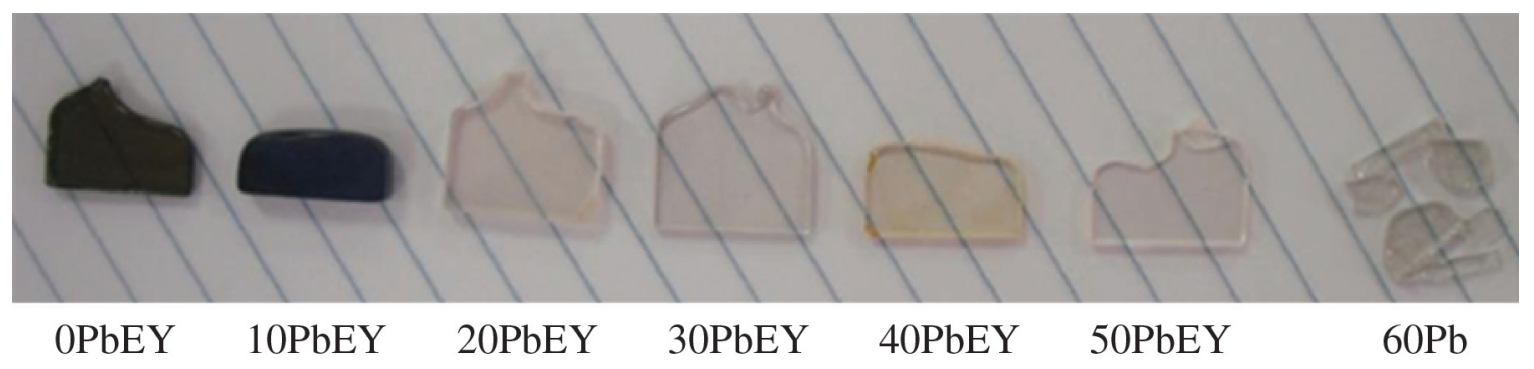

Figure 1. Glass samples obtained in the ternary system $\mathrm{NaPO}_{3}-\mathrm{WO}_{3}-\mathrm{PbF}_{2}$. 


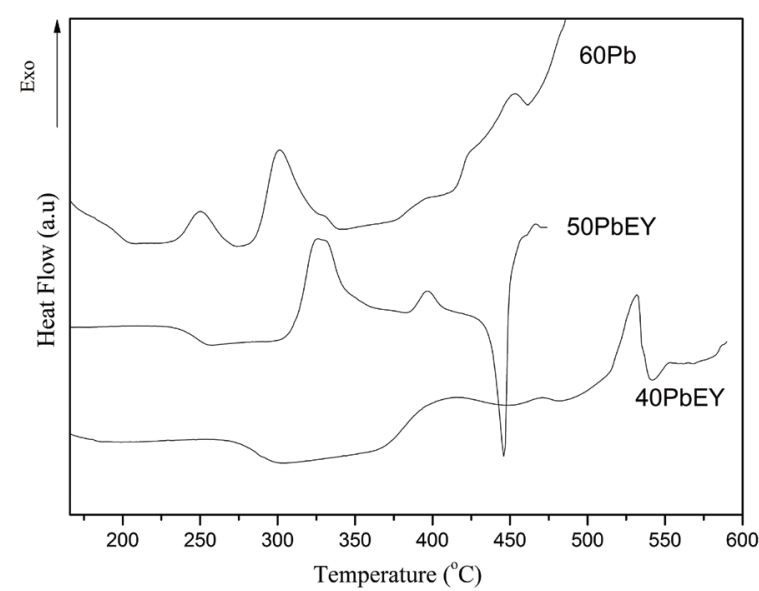

Figure 2. DSC curves of the glass samples $40 \mathrm{PbEY}, 50 \mathrm{PbEY}$ and $60 \mathrm{PbEY}$.

at $400{ }^{\circ} \mathrm{C}$ didn't induce any crystallization as shown above in this work. Sample $50 \mathrm{PbEY}$ presents to main crystallization peaks at $325^{\circ} \mathrm{C}$ and $396^{\circ} \mathrm{C}$ as well as a clear melting event at $432{ }^{\circ} \mathrm{C}$. Finally, the DSC curve of undoped sample $60 \mathrm{~Pb}$ is characterized by a first crystallization event at $250{ }^{\circ} \mathrm{C}$, a second exothermic peak at $301^{\circ} \mathrm{C}$ with a shoulder at $327^{\circ} \mathrm{C}$ and another weak exothermic event at $396{ }^{\circ} \mathrm{C}$. At higher temperatures, the baseline rise is attributed to fluoride evaporation. This distinct crystallization behavior with composition suggests that different crystalline phases can be obtained in each sample under specific annealing conditions. For these reasons, heat treatment were performed at specific temperatures for each sample and the X-ray diffraction measurements of these treated samples are resumed in Figure 3 for composition $40 \mathrm{PbEY}$, Figure 4 for composition $50 \mathrm{PbEY}$ and Figure 5 for composition $60 \mathrm{~Pb}$. As explained above, the apparent DSC baseline change for sample Pb40EY is not related with any crystallization event since this sample heat-treated for $30 \mathrm{~min}$ at $400{ }^{\circ} \mathrm{C}$ remains completely amorphous (Figure 3 ). On the other hand, heat treatment at $520{ }^{\circ} \mathrm{C}$ (above the second onset of crystallization $\mathrm{Tx}_{2}$ ) for 4 hours promotes crystallization of the lead fluorophosphate phase $\mathrm{Pb}_{5} \mathrm{~F}\left(\mathrm{PO}_{4}\right)_{3}$. Other weak diffraction peaks observed in the diffraction pattern could not be identified (labelled * in Figure 3) and may be related with precipitation of another crystalline phase identified by DSC around $470^{\circ} \mathrm{C}$. $\mathrm{X}$-ray diffraction patterns of sample $50 \mathrm{PbEY}$ heat-treated at $300{ }^{\circ} \mathrm{C}$ (onset of the first crystallization event) for 2 hours and $390{ }^{\circ} \mathrm{C}$ (onset of the second crystallization event) for 4 hours are presented in Figure 4. The first heat-treated sample is mainly amorphous since the most intense event is the diffraction halo. A very weak diffraction peak centered at $30,5^{\circ}$ is also observed. For the other sample heat-treated at higher temperature, intense diffraction peaks are observed without any residual diffraction halo, indicating the high crystallinity of this sample. Most of these diffraction peaks were attributed to the lead fluorophosphate phase $\mathrm{Pb}_{5} \mathrm{~F}\left(\mathrm{PO}_{4}\right)_{3}$, as illustrated in Figure 4. Other weak diffraction peaks (identified by $*$ in Figure 4 ) were also observed but could not be attributed to any known phase containing the elements

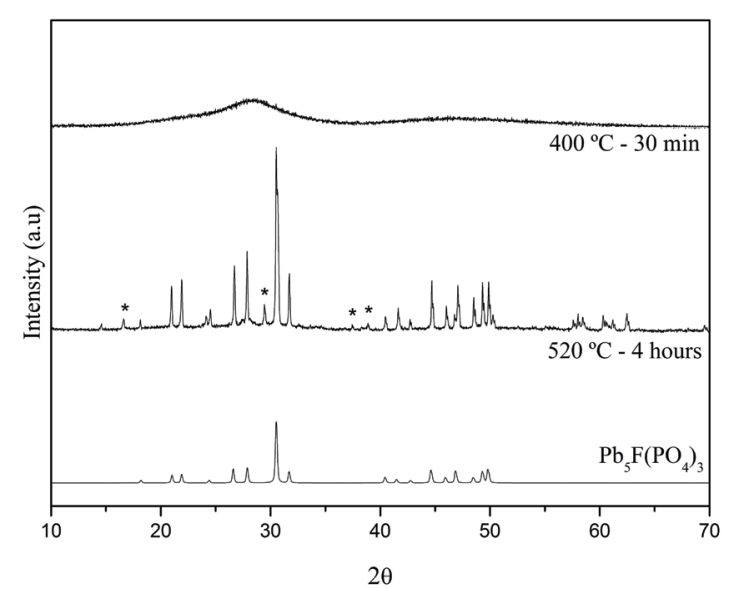

Figure 3. X-ray diffraction patterns of sample $40 \mathrm{PbEY}$ heat-treated at $400^{\circ} \mathrm{C}$ for $30 \mathrm{~min}, 520^{\circ} \mathrm{C}$ for 4 hours and crystalline $\mathrm{Pb}_{5} \mathrm{~F}\left(\mathrm{PO}_{4}\right)_{3}$ reference.

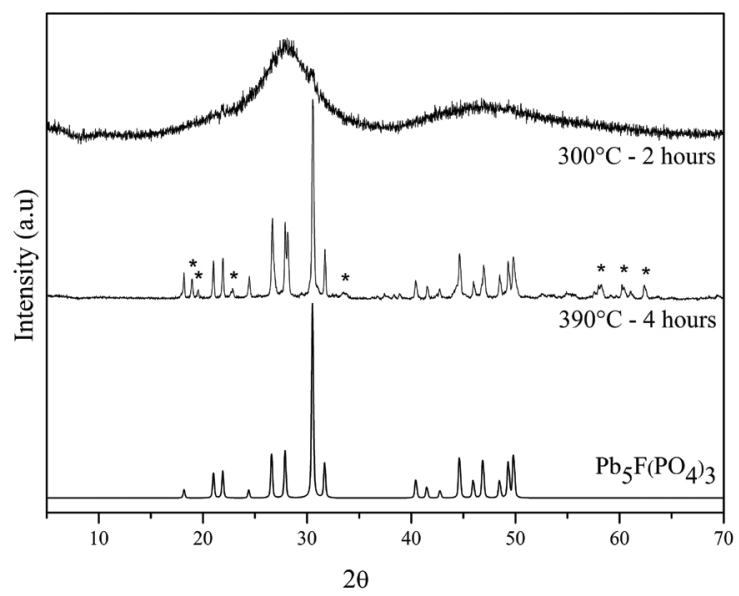

Figure 4. $\mathrm{X}$-ray diffraction patterns of sample $50 \mathrm{PbEY}$ heat-treated at $300^{\circ} \mathrm{C}$ for 2 hours, $390{ }^{\circ} \mathrm{C}$ for 4 hours and crystalline $\mathrm{Pb}_{5} \mathrm{~F}\left(\mathrm{PO}_{4}\right)_{3}$ reference.

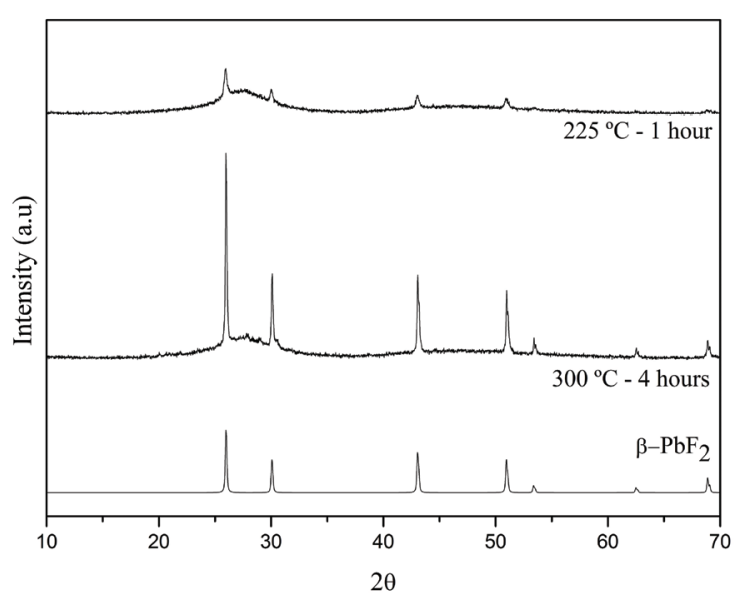

Figure 5. X-ray diffraction patterns of sample $60 \mathrm{~Pb}$ heat-treated at $225^{\circ} \mathrm{C}$ for 1 hour, $300{ }^{\circ} \mathrm{C}$ for 4 hours and crystalline $\beta-\mathrm{PbF}_{2}$ reference. 
present in our sample and are not related with any lead fluoride crystalline phase. This crystalline phase may be precipitated during the first exothermic event since the corresponding peak is not symmetric and probably constituted of several elemental components. It can also be observed from Figure 4 that the main diffraction peak of $\mathrm{Pb}_{5} \mathrm{~F}\left(\mathrm{PO}_{4}\right)_{3}$ is centered at $30,5^{\circ}$, suggesting that the weak diffraction peak observed for the sample annealed at $300{ }^{\circ} \mathrm{C}$ is also due to a early stage of $\mathrm{Pb}_{5} \mathrm{~F}\left(\mathrm{PO}_{4}\right)_{3}$ crystallization. Thus, it can be inferred that the first crystallization peak is mainly related with precipitation of $\mathrm{Pb}_{5} \mathrm{~F}\left(\mathrm{PO}_{4}\right)_{3}$. These results point out that glass compositions $40 \mathrm{PbEY}$ and $50 \mathrm{PbEY}$ are not promising for luminescent glass-ceramics since $\mathrm{Pb}_{5} \mathrm{~F}\left(\mathrm{PO}_{4}\right)_{3}$ is not a suitable crystalline host for rare earth ions due to high phonon energy of phosphate compounds. X-ray diffraction patterns of undoped sample $60 \mathrm{~Pb}$ heat-treated at $225^{\circ} \mathrm{C}$ (onset of the first crystallization event) for 1 hour and $300{ }^{\circ} \mathrm{C}$ (onset of the second crystallization event) for 4 hours are presented in Figure 5. For this sample, it could be determined that cubic lead fluoride is precipitated under heat-treatment in both cases with a higher crystallinity of the sample for higher heat-treatment temperatures. In addition, results shown in Figure 5 demonstrated that no other crystalline phase is precipitated under these conditions, suggesting that $\beta-\mathrm{PbF}_{2}$ growth can be easily controlled in the glass sample in order to achieve the desired crystallite size and distribution. These X-ray diffraction measurements are helpful to attribute the first crystallization peak to cubic lead fluoride precipitation but didn't clarify the origin of the second exothermic event. Even if the crystallization of the overall glass matrix should be expected, further specific heat treatments and X-ray characterizations must be performed on this sample to fully describe the crystallization sequence. Finally, DSC measurements were performed on the bulk and powder glass samples $50 \mathrm{PbEY}$ and $60 \mathrm{~Pb}$ to access the main crystallization mechanism which can be induced from nuclei at the surface (surface crystallization) or in the bulk (volume crystallization). When the crystallization process is induced from the surface, a large dependence of crystallization peak intensity and temperature is observed in function of the glass particle size. On the other hand, a preferential bulk volume crystallization can be identified by a similar crystallization behavior of the studied crystalline phase in the powder and bulk form. These results are presented in Figure 6. For sample 50PbEY, the very small shift of the onset of crystallization for both crystallization events is a strong indication of a preferential bulk nucleation of the corresponding crystalline phases, the first one being already attributed to $\mathrm{Pb}_{5} \mathrm{~F}\left(\mathrm{PO}_{4}\right)_{3}$. In the case of composition $60 \mathrm{~Pb}$, the first crystallization peak due to cubic lead fluoride precipitation also suffers a very small temperature shift with particle size, indicating again a dominant bulk nucleation for this crystalline phase. On the other hand, a strong temperature shift can be observed for the high temperature crystallization event, suggesting that this unidentified crystalline phase is dominantly nucleated by the surface. Since a homogeneous bulk nucleation is required for control of the crystallite growth and distribution, these thermal results are promising and suggest that this glass composition is suitable for preparation of transparent glass-ceramics containing low phonon energy $\beta-\mathrm{PbF}_{2}$. However, this glass composition could not be doped with

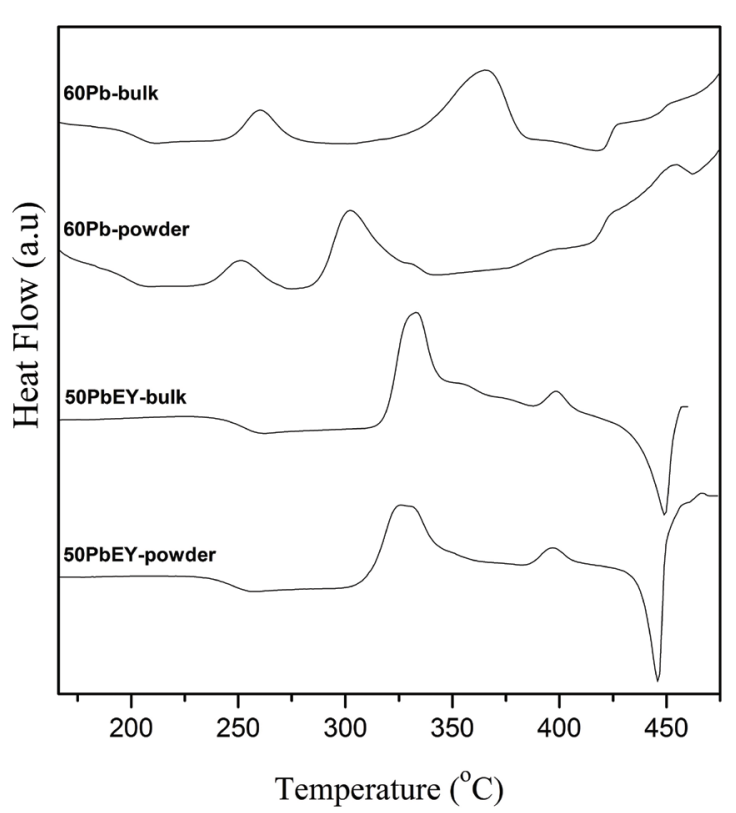

Figure 6. DSC curves of sample $50 \mathrm{PbEY}$ and $60 \mathrm{~Pb}$ in the bulk and powder form.

rare earth ions, which is a requirement for the desired applications but such doping may be achieved for lower rare earth concentrations or by varying the $\mathrm{NaPO}_{3} / \mathrm{WO}_{3}$ ratio under constant lead fluoride content in order to improve the glass stability against devitrification.

\section{Conclusion}

$\mathrm{Er}^{3+} / \mathrm{Yb}^{3+}$ codoped glass samples could be obtained in the ternary system $(100-\mathrm{x})\left[0,6 \mathrm{NaPO}_{3}-0,4 \mathrm{WO}_{3}\right]-\mathrm{xPbF}_{2}$ with $\mathrm{x}$ ranging from 0 to 50 and an undoped glass sample with $\mathrm{x}=60$ could also be prepared. The most $\mathrm{PbF}_{2}$ concentrated samples $(x=40, x=50$ and $x=60)$ were selected for thermal and crystallization characterizations. Thermal properties obtained by DSC for all samples pointed out a decrease of the glass transition temperature and glass thermal stability against devitrification related with the modifier behavior of lead fluoride. Heat-treatments performed near the crystallization peaks and X-ray diffraction measurements on the annealed samples indicated that the glass samples containing $40 \%$ and $50 \%$ of $\mathrm{PbF}_{2}$ preferentially precipitate lead fluorophosphate $\mathrm{Pb}_{5} \mathrm{~F}\left(\mathrm{PO}_{4}\right)_{3}$ whereas the glass containing $60 \%$ of $\mathrm{PbF}_{2}$ presents a first crystallization event due to $\beta-\mathrm{PbF}_{2}$ nucleated homogeneously in the bulk and without other undesirable crystalline phase. These results suggest that this glass composition is promising for transparent glass-ceramics containing $\beta-\mathrm{PbF}_{2}$ nanocrystals for optical applications.

\section{Acknowledgments}

The authors would like to thank brazilian funding agencies FAPEMIG, FINEP, CNPq and CAPES for financial support and UNIFAL-MG for the laboratory structure. 


\section{References}

1. Klein RM, Kolbeck AG and Quackenbush CL. Glass formation and properties in aluminum borophosphate system. American Ceramic Society Bulletin. 1978; 57(2):199.

2. Bih L, Allali N, Yacoubi A, Nadiri A, Boudlich D, Haddad $\mathrm{M}$, et al. Thermal, physical and spectroscopic investigations of $\mathrm{P} 2 \mathrm{O} 5-\mathrm{A}(2) \mathrm{MoO}(4)-\mathrm{A}(2) \mathrm{O}(\mathrm{A}=\mathrm{Li}, \mathrm{Na})$ glasses. Physics and Chemistry of Glasses. 1999; 40:229.

3. Brow RK and Tallant DR. Structural design of sealing glasses. Journal of Non-Crystalline Solids. 1997; 222:396-406. http:// dx.doi.org/10.1016/S0022-3093(97)90142-3.

4. Zhang L, Sun H, Wu H, Wang J, Hu L and Zhang J. Effects of PbF2 on the spectroscopic, lasing and structural properties of $\mathrm{Yb3+-}$ doped fluorophosphate glass. Solid State Communications. 2005; 135(1-2):150-154. http://dx.doi.org/10.1016/j.ssc.2005.01.053.

5. Choi JH, Margaryan A, Margaryan A and Shi FG. Optical transition properties of $\mathrm{Yb} 3+$ in new fluorophosphate glasses with high gain coefficient. Journal of Alloys and Compounds. 2005; 396(1-2):79-85. http://dx.doi.org/10.1016/j.jallcom.2004.10.076.

6. Wang Y and Ohwaki J. New transparent vitroceramics codoped with $\mathrm{Er} 3+$ and $\mathrm{Yb} 3+$ for efficient frequency upconversion. Applied Physics Letters. 1993; 63(24):3268. http://dx.doi. org/10.1063/1.110170.

7. Hirao K, Tanaka K, Makita M and Soga N. Preparation and optical properties of transparent glass-ceramics containing B-PbF2:Tm3+. Journal of Applied Physics. 1995; 78(5):3445. http://dx.doi.org/10.1063/1.359975.

8. Tick PA, Borrelli NF, Cornelius LK and Newhouse MA. Transparent glass ceramics for $1300 \mathrm{~nm}$ amplifier applications. Journal of Applied Physics. 1995; 78(11):6367. http://dx.doi. org/10.1063/1.360518.
9. Poirier G, Poulain M, Messaddeq Y and L Ribeiro SJ. New tungstate fluorophosphate glasses. Journal of Non-Crystalline Solids. 2005; 351(4):293-298. http://dx.doi.org/10.1016/j. jnoncrysol.2004.11.017.

10. Santagneli SH, de Araujo CC, Strojek W, Eckert H, Poirier G, Ribeiro SJ, et al. Structural studies of $\mathrm{NaPO} 3-\mathrm{MoO} 3$ glasses by solid-state nuclear magnetic resonance and Raman spectroscopy. The Journal of Physical Chemistry B. 2007; 111(34):1010910117. http://dx.doi.org/10.1021/jp072883n. PMid:17683136

11. Poirier G, Araújo CB, Messaddeq Y, Ribeiro SJL and Poulain M. Tungstate fluorophosphate glasses as optical limiters. Journal of Applied Physics. 2002; 91(12):10221.

12. Poirier G, Nalin M, Cescato L, Messaddeq Y and Ribeiro SJ. Bulk photochromism in a tungstate-phosphate glass: a new optical memory material? The Journal of Chemical Physics. 2006; 125(16):161101. http://dx.doi.org/10.1063/1.2364476. PMid:17092055

13. Poirier G, Nalin M, Ribeiro SJL and Messaddeq Y. Photochromic properties of tungstate-based glasses. Solid State Ionics. 2007; 178(11-12):871-875. http://dx.doi.org/10.1016/j.ssi.2007.01.012.

14. Poirier G, Jerez VA, De Araújo CB, Messaddeq Y, Ribeiro SJL and Poulain M. Optical spectroscopy and frequency upconversion properties of Tm[sup 3+] doped tungstate fluorophosphate glasses. Journal of Applied Physics. 2003; 93(3):1493-1497. http://dx.doi.org/10.1063/1.1536017.

15. International Centre for Diffraction Data - ICDD. Joint Committee of Powder Diffraction Standards - JCPDS. Powder diffraction file: PDF. 2000 .

16. Poirier G, Ottoboni FS, Cassanjes FC, Remonte A, Messaddeq $\mathrm{Y}$ and Ribeiro SJ. Redox behavior of molybdenum and tungsten in phosphate glasses. The Journal of Physical Chemistry $B$. 2008; 112(15):4481-4487. http://dx.doi.org/10.1021/jp711709r. PMid:18358031 